\title{
COVID-19 and Its Impact on Tobacco Use - Is India Prepared to Unlock the link?
}

\author{
Radhakrishnan Jayakrishnan
}

\section{ABSTRACT}

Reports from around the globe has highlighted that people with existing non communicable diseases when infected with COVID 19 are highly vulnerable to severe ill effects. Considering the fact that tobacco use is associated with many of the non-communicable diseases it is important to incorporate tobacco control measures as well into the broader prevention arena of the COVID 19 control strategy. Considering the economic costs associated with the treatment of tobacco related diseases, it is important for a developing country like India to grab this opportunity to undertake sensitization campaigns against COVID 19 and its consequences among tobacco users. Further promotion of tobacco cessation campaigns using toll free quit line support mechanisms in regional languages, online platforms and print and visual media needs to be done keeping in mind a favorable net result in the long run.

Keywords: COVID-19, tobacco, India.

\section{INTRODUCTION}

Ever since the COVID-19 pandemic struck India when the first case was reported in the state of Kerala, a lot of public health measures have been envisaged and implemented to check the outspread of the virus. According to the Ministry of Health and Family Welfare, Government of India, 9,44,996 active cases and 100,842 deaths were reported as on October $3^{\text {rd }}, 2020$ [1]. Apart from the universally accepted and cost-effective way of practicing 'SMS' that points to the trio of Sanitise-Mask-Social distancing, additional measures are being adopted to check the virus spread. These include legal measures to implement SMS and infrastructure development for investigating and reporting the disease, followed by isolation, treatment, and rehabilitation. All these measures viz. fear of illness, infective period, isolation, persistent lockdown, anxiety on job security and loss of wages could have a profound impact on the psyche of the common man. In addition, among substance users, the unavailability of the product during lock down could result in either to face negative emotions or seek refuge in substance use procured through illicit means [2]. On the other hand, the pandemic period has given the tremendous possibility of revamping one's life by quitting the habit and to lead a healthy life.

\section{COVID-19 IMPACT ON TOBACCO USE}

In spite of the efforts to contain the COVID-19 pandemic that has ravaged the day to day spheres of life globally in one way or the other, there are certain lessons that need to
Published Online: December 16, 2020

ISSN: $2593-8339$

DOI: $10.24018 /$ ejmed.2020.2.6.602

Radhakrishnan Jayakrishnan*

Division of Community Oncology \& Tobacco Cessation Clinic, Regional Cancer Centre, Thiruvananthapuram, India.

(e-mail: jaykrishnan999@ gmail.com)

*Corresponding Author be learned to overcome this gruesome scenario. In a large country like India with more than a billion population striving to overcome this situation, it is important to know that some of the existing public health problems could also be controlled if effective measures are taken to control the spread of the virus. One such factor is the practice of tobacco use in India. Tobacco use in India is more intricate considering the variety of tobacco products available in the market, its accessibility and affordability, supplemented by the socioeconomic disparity prevailing in the society and its association with tobacco use. India has the second highest number of tobacco users in the world where 266.8 million (28.6\%) adults use tobacco in some form or the other. This corresponds to 199.4 million smokeless tobacco (SLT) users and 99.5 million smokers [3]. It was estimated that $12,80,000$ deaths per year are attributed to tobacco use in India [4]. The economic cost attributed to tobacco consumption from all diseases among middle aged group in the country was reported to be 22.4 billion US\$ in the year 2011 [5]. Considering the fact that socioeconomically deprived people are more vulnerable to take up and continue the habit, stringent public health measures are required to control the problem.

Reports from around the globe has highlighted that people with existing non communicable diseases when infected with COVID-19 are highly vulnerable to severe ill effects [6], [7]. Considering the fact that tobacco use is associated with non communicable diseases mainly chronic obstructive pulmonary disease, hypertension, cardiovascular disease, cancer and diabetes, it is important to incorporate tobacco control measures as well into the broader prevention arena of the COVID-19 control strategy. 
Smoking tobacco results in frequent contact of fingers with the lips increasing the possibility of virus transmission from hand to mouth. If the person gets infected, the risk of pulmonary infection, because of upper airway damage, eventually resulting in impaired lung function is high. The possibility of virus transmission among tobacco users is assumed to be more, when lighted cigarettes or bidis are often shared and passed from one person to another ignoring social distancing practice. Even sharing of hookah or water pipes while smoking might have the same outcome [8]. These types of practices are commonly seen in rural areas particularly during social gatherings in India. The saliva tinged tobacco product could act as a source of virus transmission because the highly contagious virus spreads through droplets of saliva and nasal discharge when a person coughs or sneezes. In addition to this, the likelihood of virus transmission to non-smokers particularly among their households and community has to be looked upon in view of the contagious nature of the virus [4]. In case of SLT users, the transmission mode assumes significance considering the nature of its use. It has been reported that more than 40 different types of SLT are sold in the market globally of which 30 are used in India and Bangladesh [9], [10]. Chewing tobacco brings out more saliva in the oral cavity and the urge to spit also increases prompting the SLT user to spit often. Hence the risk of contaminating public places is high which in turn could be a route of spread of the virus. While considering the tobacco products prepared by a pan vendor, when the customer demands for it, the product contamination risk is again high, if the hand sanitization by the vendor was not done properly.

\section{THE WAY FORWARD}

The COVID-19 pandemic has given the opportunity to redefine the importance of cleanliness, keeping good hygiene and the practice of promoting good health for a healthy living and a healthy nation. The Government of India has currently banned spitting in public places and violation of this rule is a punishable offence in its revised guidelines for lockdown issued under the Disaster Management Act 2005 to control the COVID-19 spread. It would be useful to undertake a nationwide survey on the tobacco use prevalence in the current scenario and how far it was helpful to quit the habit given this circumstance. It is expected that withdrawal symptoms, stress and anxiety could be challenging for many tobacco users during this period. Toll free quit line support mechanisms for tobacco cessation in regional languages and the e-Sanjeevani National Tele Consultation Service of the Government of India would come a long way in handling the problem. In addition to this, for tobacco users infected with the virus, the COVID-19 treatment centres could also facilitate assistance in the form of counseling and medication for those who are in need.

\section{CONCLUSION}

The impact of COVID-19 on people with preexisting noncommunicable diseases is disturbing considering their vulnerability to become severely ill. Exposure to tobacco being one of the important risk factors for NCD's, the current scenario offers valuable insights for the community to understand the magnitude of the problem and the ways and means to counter the existing situation. In view of the economic costs associated with the treatment of tobacco related diseases, it is important for a developing country like India to grab the opportunity to undertake sensitization campaigns against COVID-19, its consequences among tobacco users and further promotion of tobacco cessation campaigns in online platforms, print and visual media. In this COVID-19 crisis period, it is expected that the tobacco use might have decreased given the circumstance that prevailed globally which has its reflections in India. Hence, it is hypothesized that in the long run, the risk of tobacco related diseases in India is likely to decrease if the tobacco demand and supply chain are at an all-time low taking into account the COVID-19 situation as a benchmark to achieve the desired result.

\section{REFERENCES}

[1] Ministry of Health and Family Welfare, Government of India [home page on the internet]. COVID -19 India as on 03 October, 2020 Available from: https://www.mohfw.gov.in/, accessed on October 3, 2020 .

[2] Subodh BN, Mahintamani T. COVID-19 and Tobacco Use: A Review. J Postgrad Med Edu Res 2020;54(3):108-111.

[3] GATS. Global Adult Tobacco Survey: fact sheet, India 2016-17 [home page on the internet]. Available from: http://www.who.int/tobacco/surveillance/survey/gats/GATS_India_20 16-17_FactSheet.pdf/, accessed on August 10, 2020.

[4] Ministry of Health and Family Welfare, Government of India. COVID- 19 Pandemic and Tobacco Use in India. Available from: https://www.mohfw.gov.in/pdf/COVID19PandemicandTobaccoUsein India.pdf accessed on September 22, 2020

[5] John RM, Rout SK, Kumar BR, Arora M. Economic burden of tobacco associated diseases in India, New Delhi. Ministry of Health and Family Welfare, Government of India; 2014

[6] BASU S. Non-communicable disease management in vulnerable patients during Covid-19. Indian Journal of Medical Ethics . 2020 2:103-5.

[7] Palmer K, Monaco A, Kivipelto M, Onder G, Maggi S, Michel JP et al. The potential long-term impact of the COVID-19 outbreak on patients with non-communicable diseases in Europe: consequences for healthy ageing. Aging Clin Exp Res. 2020; 32(7):1189-94

[8] World Health Organisation. \#HealthyAtHome- Quitting tobacco. Available from https://www.who.int/campaigns/connecting-theworld-to-combat-coronavirus/healthyathome/healthyathome--quitting-tobacco, accessed on October 1, 2020.

[9] Thakur JS, Paika R. Determinants of smokeless tobacco use in India Indian J Med Res. 2018;148(1):41-45.

[10] Niaz K, Maqbool F, Khan F, Bahadar H, Ismail Hassan F, Abdollahi M. Smokeless tobacco (paan and gutkha) consumption, prevalence, and contribution to oral cancer. Epidemiol Health. 2017; 39. e2017009. 